Business and Economics Research Journal

Volume 8 Number 12017

pp. $1-18$

ISSN: $1309-2448$

DOI Number: 10.20409/berj.2017126241

\title{
Total Factor Productivity and Efficiency in OECD Countries: Possibility of Convergence in 2000-2012 Period
}

\author{
Aziz Kutlar
}

Ali Kabasakal ${ }^{\text {b }}$

Ahmet Gülmez

\begin{abstract}
This study discusses efficiency, productivity, and the existence of convergence in 34 OECD countries between 2000 and 2012. Physical capital per worker and human capital per worker are used as inputs to determine total factor productivity and efficiency scores in data envelopment analysis while GDP per worker is used as the output. Efficiency scores observed in CCR and BCC models indicate that Latin American and Eastern European countries are more efficient. Analysis of productivity by using the Malmquist Index indicates that productivity was positive but increased less than 1 percent at the end of the period. Panel regression estimation is used for standard deviations of convergence and to determine beta convergence. If GDP per worker is $\left(y_{i}\right)$, there is convergence between $\log \left(y_{i} / y_{\left.i, t-T_{1}\right)}\right)$ and starting values $\log \left(y_{i, t-T}\right)$; however, the convergence effect of TFP values could not be determined. Similar results are reported for Sigma convergence.
\end{abstract}

Keywords: Panel Data, Malmquist Index, TFP, OECD countries, Convergence

JEL Classification: C23, C43, D24, 047

\section{Introduction}

The Organization for Economic Co-operation and Development (OECD) was established in 1961 and has 34 members. The OECD budget is approximately $\$ 357$ million. During the study period, total real gross domestic product (GDP) rose by 22 percent, reaching $\$ 39$ trillion. Capital increased by 8 percent, reaching \$7.8 trillion, while labor power increased 11 percent, reaching 610 million people within the same period (https://data.oecd.org/). GDP growth was greater than capital and labor power growth. There was significant total factor productivity growth in OECD countries.

Income distribution and differentiation among OECD countries, which are the leading economies of the world, are increasing (http://oecd/idd). The ratio of the top 10 percent to the bottom 10 percent is estimated to be 9.5 percent in 2012; however the relevant figure was 7 percent in 1980 . The difference between the rich and the poor requires examining convergence and divergence among the relevant countries.

Growth dynamics of countries as well as convergence among those countries have been studied for a long time according to neoclassical growth theories in various studies. A series of studies indicate convergence among OECD countries. The majority of such studies use productivity per worker and total

aProf. Dr., Sakarya University, Faculty of Political Sciences, Department of Economics, Sakarya, Turkiye, akutlar@sakarya.edu.tr

${ }^{b}$ Assoc. Prof. Dr., Sakarya University, Faculty of Political Sciences, Department of Economics, Sakarya, Turkiye, kabasakal@sakarya.edu.tr

'Assist. Prof. Dr., Sakarya University, Faculty of Political Sciences, Department of Economics, Sakarya, Turkiye, agulmez@sakarya.edu.tr 
factor productivity in order to analyze convergence. The case of "Solow residual" is named after Solow (1957); that part of growth is known as Total Factor Productivity (TFP).

The economic productivity and convergence issue of OECD countries, the economic structures of which are partially similar to each other and that are representative of relatively advanced economies, has been investigated by our study for the period between 2000 and 2012. In that regard, MI, which is interpreted by Caves et al. (1982), and the data envelopment analysis (DEA) method used by Charnes et al. (1978) are used for TFP. The description is used as inputs and outputs. Physical capital is used as input and is among some of the most important factors that affect technological development and productivity. Gross national product is used as output. All variables are divided into labor unit and necessary analyses are performed. Data sources are provided below. The whole variable value is calculated based on 2005 U.S. dollars. A total of 34 OECD countries are included in the analysis. Although some of the countries were not OECD member during the entire given period, they are still included. Whether there are any differences between these countries will be observed during the analysis process.

The aim of this study is to analyze convergence in OECD countries over a reasonable period of time at the beginning of the new millennium. The period between 2000 and 2012 is chosen intentionally in order to examine the results of the financial crisis of 2009. Another reason for the short study period is our effort to include DEA, Malmquist, and convergence analyses together. Including more data sets would have expanded the DEA and TFP tables, which in turn would exceed the limits of this study. The study period has given us the chance to employ all three analyses. The set of values in the study are obtained from OECD StatExtracts. Real physical capital per worker, real human capital per worker, and real GDP per worker are calculated based on 2005 U.S. dollars.

The literature and methodology forms the first part of the study while the results of the DEA and Malmquist index (MI) analysis of TFP are given in the following chapter. The conclusion and assessment make up the last part of this study.

\section{Literature}

In recent years there have been many studies that examine convergence and economic growth. Barro and Sala-i Martin $(1991,1992)$ and Färe et al. (2006) are the major contributors to the relevant literature. According to Krüger (2003), experiential growth investigations over the last ten years have been pursued at least three different ways. First, the most immense strand of literature applies linear regressions to clarify the growth ratio of real GDP per capita by a great amount of different growth driving factors while at the same time struggling to anticipate the ratio of convergence of countries to their steady state positions. Second, some studies provide new anticipations of ratio of total factor productivity growth on an economywide scale as precautions of technological progress. The third basic approach of experiential growth searches for the dynamics of the entire distribution of real GDP per capita or per worker. The second significant issue forms the focus of interest of a range of studies that aim to find whether the economies of two such country groups converge with one other (Barro and Sala-i-Martin 1991, 1992; Mankiw et al. 1992).

In their study regarding growth and productivity in OECD countries, Dowrick and Nguyen (1989) analyzed the hypothesis that GDP levels and total factor productivity in OECD countries converged following the postwar period. Their findings suggest that convergence of income levels had been weak since 1973; however, they argue that income convergence is contingent upon sample selection and that TFP catch-up is the prevailing trend. In the study concerning the EU countries conducted by Färe et al. (2006), growth in productivity and the phenomenon of convergence was investigated during the period between 1965 and 1998. Efficiency and productivity of human and physical capital are examined as inputs. The existence of convergence among these countries is also investigated. Additionally, relevant countries are divided into subgroups and the existence of a single "convergence club" is investigated.

Margaritis et al. (2007) conducted a similar study to that of Färe et al.'s (2006) and developed it further. In the productivity and convergence analysis of OECD countries between 1979 and 2002 by Margaritis et al. (2007), which is one of the most comprehensive studies concerning productivity and 
convergence among OECD countries, various tests are applied using the time series method as well as $\sigma$ and $\beta$ calculation techniques. Afterwards, the analysis is extended to 1960 by developing the field of series, confirming convergence for the OECD countries. In another study conducted among OECD countries by using the $\beta$ convergence test by Maudos et al. (2000), labor productivity convergence was investigated. Following a range of analyses, the existence of convergence between labor productivity and the relevant countries is observed; however, the level of convergence was low.

In another study, in which a different methodology is used to analyze growth and convergence in OECD countries (Yörük and Zaim 2005), factor productivities measured using the MI and the Malmquist Luamberger index are examined. Furthermore, taking Lee's (2009) study into consideration, in which he examines time series properties of long-run productivity convergence of 25 sample countries between 1975 and 2004 by performing panel unit-root procedure, similar studies can be found that investigate the 34 OECD countries in terms of efficiency and convergence.

Chen and Yu (2014) included not only OECD countries but some other country categories as well in order to increase the number of countries in the study. They studied the total factor productivity of 99 countries. Their study examines the capital-using/labor-saving, capital-using/energy-saving, and energy using/labor-saving tendencies of the countries. Their findings suggest that most of the countries profit from advantages of technological innovation. Madsen (2007) examines the imports of technology and total productivity in OECD countries between 1870 and 2004. The study focuses on the transmission of knowledge through trading among the relevant countries over a period of 135 years. His findings prove that patent flows and information reflections that result from the trade route among countries complicate convergence. Rivera-Batiz and Romer's (1991) study on the internal growth approach state that R\&D information obtained as a result of trade between developed nations is reflected in such countries by means of a trade route and consequently affects TFP and increases productivity.

Some studies on OECD countries discuss sectorial growth and convergence analyses. Convergence analysis of India by Kumar and Managi (2012) and convergence analysis of the pulp and paper industries of OECD countries between 1991 and 2000 by Hseu and Shang (2005) together with Sondermann (2014), (Margaritis (2007), Kumar and Russell (2002), Maudos et al. (2000), and the approach that the productivity growth accounting approach to the ranking of developing and developed nations by Raab and Feroz (2007) are several studies covering the same subject. There are some studies that investigate convergence on an industrial basis. Shestalova's (2002) study examines the productivity of the manufacturing sectors of eleven OECD countries between 1970 and 1990; the findings of the study suggest that only the chemical industry showed strong convergence levels.

The relationship between technology transfer and convergence in developed and developing economies is a widely discussed topic as well. Given that sufficient technological transfers are not provided, it might be difficult for developing countries to catch up with developed economies. With respect to technological catch-up and capital deepening, it is essential to emphasize the thesis by Kumar and Russell (2002) that states that technological development is not detached. In other words, convergence leads to contrary divergence.

\section{Methodology}

Debreu (1951), Koopmans (1951), and Farrell (1957) are prominent scholars who apply the analysis of efficiency in economic literature and a great deal of research concerning efficiency measurement has been conducted following their work. Use of the frontier function has grown into a significant part of efficiency measurement. The parametric and non-parametric methods in these studies, in which performance evaluation is measured with regards to economic efficiency (EE), technical efficiency (TE), and allocative efficiency ( $A E)$, have common research applications.

The parametric approach includes deterministic and probabilistic patterns. In non-parametric analyses, the feature of any exclusive functional form is not required to describe the efficient frontier or surrounding surface, such as in the study by Charnes et al. (1978). 


\subsection{Structure of DEA and Efficiency}

Efficiency could be defined as an effort to get the highest output by choosing the method that uses the input composition in the most productive way. The definition implies that quantity obtained from one output cannot be increased without reducing one of the outputs by changing the input distribution economically.

According to Koopmans's description (1951), the production limit is described as $f\left(x_{t}, y_{t}\right)=0$, so $f\left(x_{t}, y_{t}\right)<0$ explains the production limits technically not being efficient. When $f\left(x_{t}, y_{t}\right)>0$, it produces inputoutput compositions which are not possible to produce by using a definite production technique (Kumbhakar and Lovell 2000). Koopmans's description has two states, one is input oriented and the other is output oriented.

i. A functionally input oriented TE is indicated as follows:

$$
T E_{1}(y, x)=\min \{\phi: \phi x \in P(y)\}
$$

ii. A functionally output oriented TE is indicated as follows:

$$
T E_{0}(x, y)=[\min \{\phi: \phi y \in P(x)\}]^{-1}
$$

Given that a decision making unit (DMU) produces outputs $y_{i},(i=1,2, \ldots, t)$ from inputs $x_{k},(k=1,2, \ldots, m)$, the equation can be explained in the following way by the relevant weights $\left(v_{i}=1,2, \ldots, t ; w_{k}=1,2, \ldots, m\right)$ applied to variables:

$$
0 \leq \sum_{i=1}^{t} v_{i} y_{i c} / \sum_{k=1}^{m} w_{k} x_{k c} \leq 1 \quad(c=1,2, \ldots, p, \ldots, z) ; \quad v_{i}, w_{k}>0\left(v_{i}=1,2, \ldots, t ; w_{k}=1,2, \ldots, \quad m\right)
$$

" $v$ " and " $w$ " account for the weights on inputs and outputs and variables in the equation. The model provides us with an efficiency value of $\mathrm{p}^{\text {th }} \mathrm{DMU}$ and a set of required weights to obtain the relevant value.

Fractional program utilizes the TFP rate. In other words, DEA should be considered as a conceptual model and the linear model is a practical method for efficiency calculations. In DEA, weights are determined pertaining to the DMUs for each input and output. DEA includes inputs $\left(x_{k}\right)$ and outputs $\left(y_{i}\right)$ in the equation as mentioned above and chooses weights in order to maximize performance of DMU " $p$ " concerning the performances of other units:

$$
\operatorname{Max} v_{i} w_{k}\left(\sum_{i=1}^{t} v_{i} y_{i p} / \sum_{k=1}^{m} w_{k} x_{k p}\right)
$$

Solution of the non-parametric efficiency measurement model in the fractional programming form is changed to a linear programming model which is relatively easier to solve (Charnes et al. 1978, 1979; Banker et al. 1984).

\subsection{Malmquist Index}

$\mathrm{MI}$ is one of the indices investigating change in production (Malmquist 1953). Applied in the DEA of Caves et al. (1982), the index comprises of different functions which stand for multi-output and multi-input technologies that are based on input and output amounts. In short MI, which is defined as CCD with the names of these authors, is the indexing of amounts in terms of distance functions. 
Linear programming methods of database studies (Charnes et al. 1978) could be used in productivity performance with regards to DEA. Solution of the relevant problem coincides with Farrell's (1957) TE measurement.

A DEA estimation method is presented for Malmquist productivity index in Cooper et al. (2011), which is the combination of the studies of Färe et al. (1994a, 1994b, 2011), Farrell (1957), Charnes et al. (1978), and Caves et al. (1982). According to Färe et al. (1994b) in $S^{t}$ production technology, $t=1$...T for each period, output based $\mathrm{MI}$, which indicates the productivity change, models the conversion of inputs $x^{t} \in R_{+}^{N}$ to outputs $y^{t} \in R_{+}^{M}$. It is described as $S^{t}=\left[\left(x^{t}, y^{t}\right): x^{t}\right.$ can produce $\left.y^{t}\right]$.

Output distance function defined in " $\mathrm{t}$ " period (Färe, 1988) is as follows:

$$
D_{o}\left(x^{t}, y^{t}\right)=\inf \left[\theta:\left(x^{t}, y^{t} / \theta\right) \in S^{t}\right]
$$

This function defines inputs, $x^{t}$, and maximum output vector, $y^{t}$. This function is first-degree homogeneous and its value is $\leq 1$. If the technology is over the frontier, $D_{0}\left(x^{t}, y^{t}\right)=1$. According to Farrell (1957) this situation indicates TE. A similar description could be made for $\mathrm{t}+1$ period as well.

Output-based CCD-type Malmquist productivity change index is the geometric mean of MI;

$$
M_{o}\left(x^{t+1}, y^{t+1}, x^{t}, y^{t}\right)=\left[\frac{D_{o}^{t}\left(x^{t+1}, y^{y+1}\right)}{D_{o}^{t}\left(x^{t}, y^{t}\right)} \frac{D_{o}^{t+1}\left(x^{t+1}, y^{t+1}\right)}{D_{o}^{t+1}\left(x^{t}, y^{t}\right)}\right]^{0.5}
$$

This index can be rewritten as a product of two different parts:

$$
M_{o}\left(x^{t+1}, y^{t+1}, x^{t}, y^{t}\right)=\overbrace{\frac{D_{o}^{t+1}\left(x^{t+1}, y^{t+1}\right)}{D_{o}^{t}\left(x^{t}, y^{t}\right)}}^{E C} \overbrace{\left[\left(\frac{D_{o}^{t}\left(x^{t+1}, y^{y+1}\right)}{D_{o}^{t+1}\left(x^{t+1}, y^{t+1}\right)}\right)\left(\frac{D_{o}^{t}\left(x^{t}, y^{t}\right)}{D_{o}^{t+1}\left(x^{t}, y^{t}\right)}\right)\right]^{0.5}}^{T C}
$$

The part of index outside the brace indicates proportional efficiency change between two periods, and the index inside the brace indicates technical change. This MI equation can be defined briefly in two parts as follows:

$$
M_{o}^{t, t+1}=E C^{t, t+1} T C^{t, t+1}
$$

In this study, for each " $t$ " period, ( $t=2000, \ldots, 2012)$, for each " $k$ " country $(k=1, \ldots, 34$; all OECD countries including recently joined ones) two inputs and one output are used.

\subsection{Convergence}

The lack of convergence across countries is an unusual finding as it suggests that cross-country income equality tends to increase and that countries that are projected to be richer a few decades from now are the same countries that are rich today. This finding is not compatible with widely accepted neoclassical growth theories (Solow 1956; Swan 1956; Cass 1965; and Koopmans 1965).

The idea behind the abovementioned conclusion is the following: the assumption of diminishing returns to capital implicit in the neoclassical production function predicts that the rate of return to capital is quite large when the stock of capital is small and vice versa. If countries only differ in terms of their initial levels of capital then, according to neoclassical growth model, which indicates cross-country betaconvergence, countries with little capital will be poor and will grow faster than rich countries. 
This anticipation is not compatible with the endogenous growth model (Romer 1986). Such models depend on the existence of externalities, increasing returns, and the lack of inputs that cannot be accumulated. The fundamental point of such models is the lack of diminishing returns to capital, so these models do not exhibit similarities with the neoclassical model in terms of convergence.

When analyzing convergence, the studies by Barro and Sala-i-Martin (1991), Mankiw et al. (1992), Barro and Sala-i-Martin (1995), and Sala-i-Martin (1996a) are usually referred to by economists. The concepts of $\beta$-convergence and $\sigma$-convergence are prevalent in classical economic growth literature.

If poor economies tend to grow faster than wealthy ones then there is $\beta$-convergence. In other words, a negative relationship between the growth rate of income per capita and the initial level of income suggests $\beta$-convergence in a cross-section of economies. That concept of convergence is usually mistaken for $\sigma$ convergence as the dispersion of real per capita income across groups of economies tends to fall over time. These two concepts examine conceptually different phenomena: $\sigma$--convergence studies the distribution of income over time and $\beta$-convergence studies the mobility of income within the same distribution. Despite the differences, these two convergences are related. Suppose that $\beta$-convergence holds for a group of regions $i$, where $i=1 \ldots . . N$. In a given time period, which likely corresponds to annual data, the real per capita income for economy $i$ can be approximated ${ }^{1}$ by

$$
\log \left(y_{i t}\right)=\alpha+(1-\beta) \log \left(y_{i, t-1}\right)+u_{i t}
$$

where $\alpha$ and $\beta$ are constants, with $0<\beta<1$, and $u_{i}$ is a disturbance term. The condition $\beta>0$ suggests $\beta$ convergence since the annual growth rate $\log \left(y_{i t} / y_{i, t-1}\right)$ is inversely related to the $\log \left(y_{i, t-1}\right)$. A higher coefficient $\beta$ indicates a greater tendency for convergence. The disturbance term captures temporary shocks to the production function, the saving rate, and so on. We assume that $u_{i t}$ has a mean of zero, the same variance, $\boldsymbol{\sigma}_{u}{ }^{2}$, for all economies, and is independent of time and different economies.

If $\beta$-convergence holds $(\beta>0)$, then $\sigma_{t}^{2}$ monotonically approaches its steady-state value, $\left(\sigma^{2 *}\right)$. The key point is that $\sigma_{t}^{2}$ can rise or decline towards the steady-state depending on whether the initial value of $\sigma^{2}$ is above or below the steady-state. In particular, $\sigma$ could rise along the transition even if $\beta>0$. In other words, $\beta$-convergence is a necessary but it is not a sufficient condition for $\boldsymbol{\sigma}$-convergence.

Departing from the works of Barro and Sala-i-Martin (1991), Mankiw et al. (1992), and Sala-i-Martin (1996b), we can distinguish conditional from absolute convergence. We claim that a series of economies exhibit conditional $\beta$-convergence if the partial correlation between growth and initial income is negative. In other words, if cross-sectional regression is applied on initial income we find that the coefficient on initial income is negative, which in return suggests that economies in the data set exhibit conditional $\beta$ convergence. If the coefficient of initial income is negative in a univariate regression, we conclude that the data set exhibits absolute convergence.

\section{Empirical Evidence}

In this study, efficiency and productivity variables and convergences of OECD countries between 2000 and 2012 are investigated. Although some countries joined OECD later, they are still included in the calculations as if they were permanent members.

While physical capital per worker and human capital per worker are used as inputs, GDP per worker is used as output. All the values are calculated in real 2005 U.S. dollars. For DEA Efficiency, output-oriented Charnes, Cooper, and Rhodes, (1978) (CCR) model with constant return to scale and the output-oriented Banker, Charnes, and Cooper, (1984) (BCC) model with variable return to scale are applied. The output oriented and constant return to scale method is applied to MI. While Kumar and Managi (2012) used similar inputs and outputs for India, Wu et al. (2013) applied it for 21 OECD countries. Despite the use of a range of software in our analyses, the software used by Coelli et al. (2005) is preferred for empirical results. 


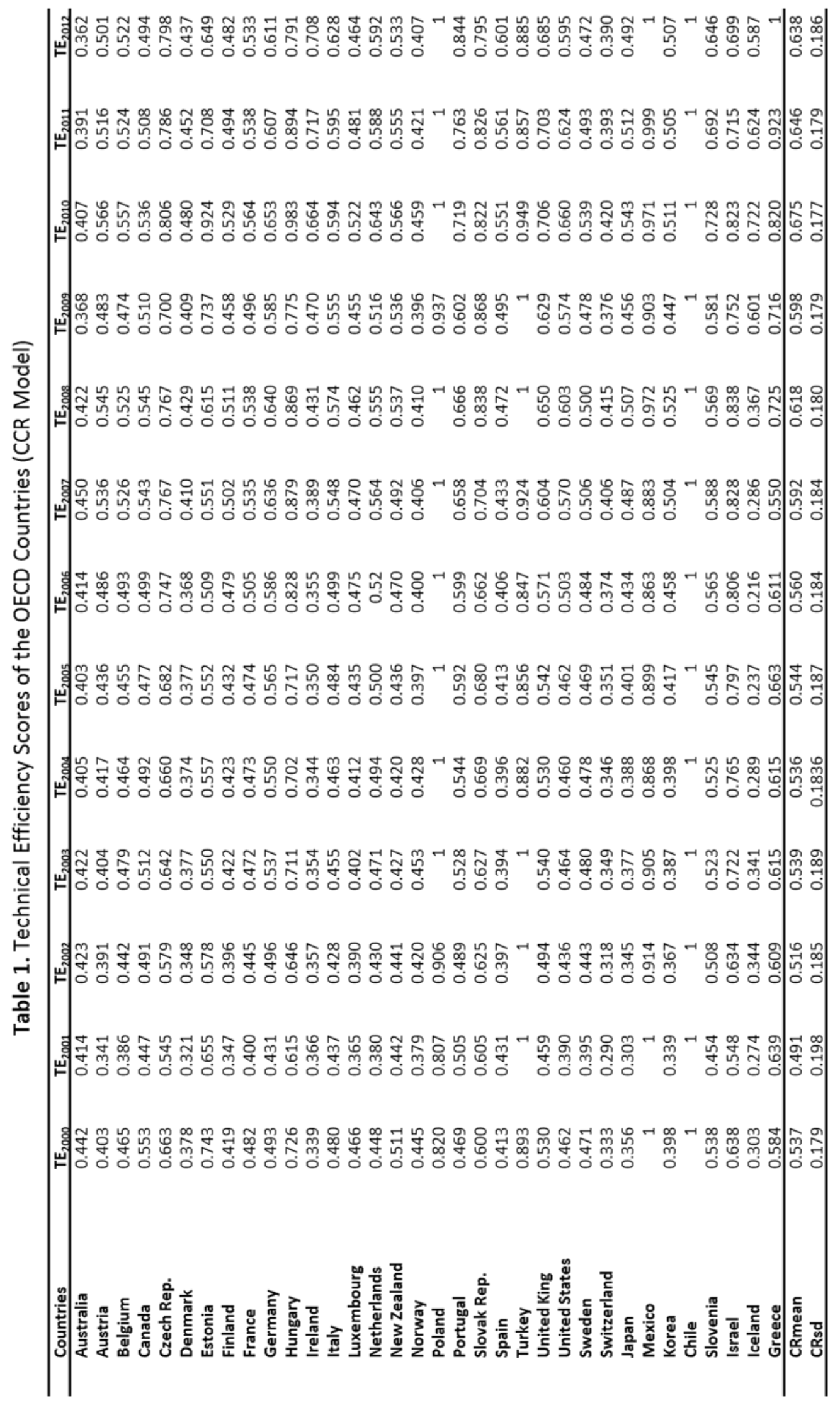




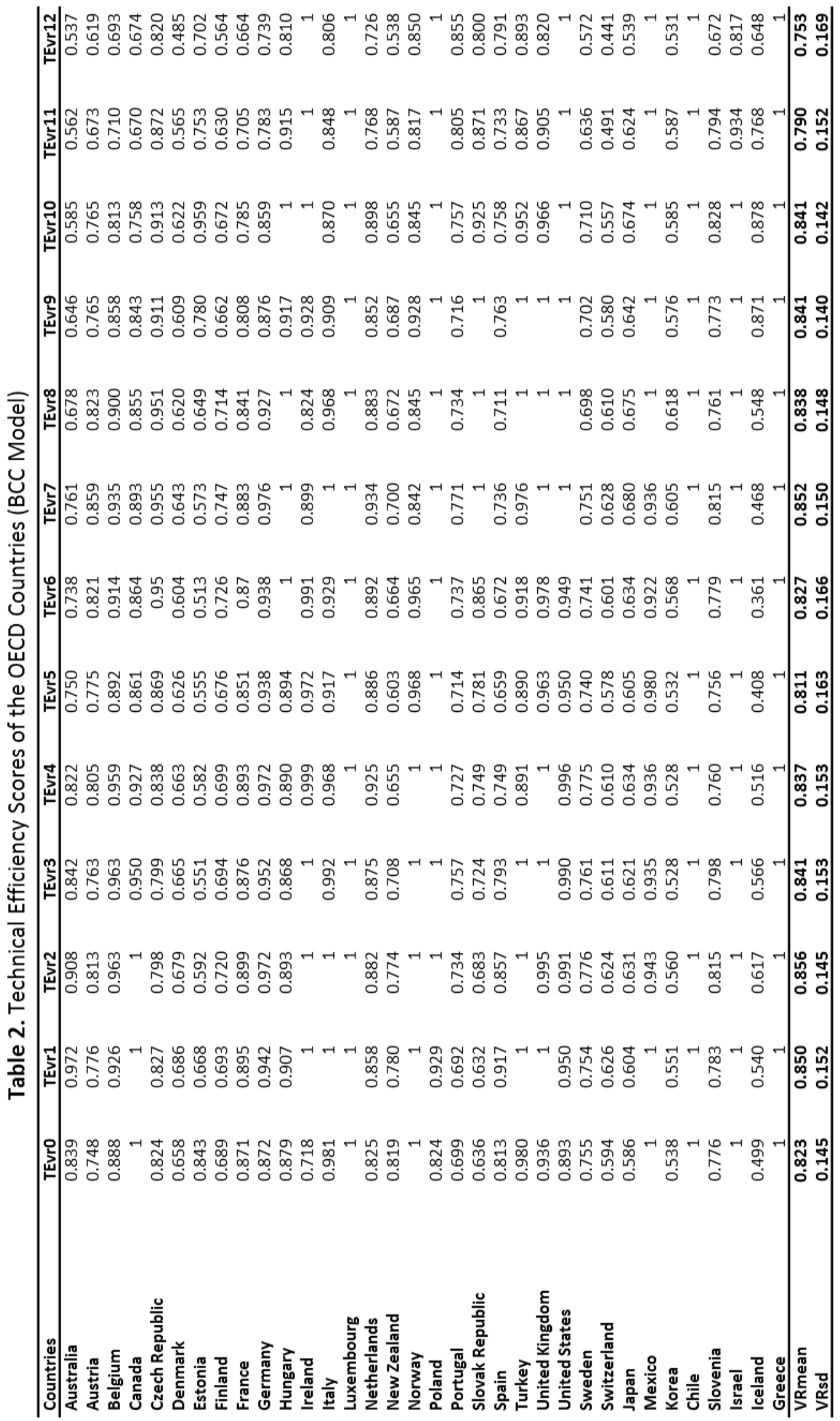




\subsection{Technical Efficiency Scores}

Efficiency scores of OECD countries over thirteen years (2000-2012) according to the CCR model are shown in Table 1. Only the input oriented with constant return to scale DEA technique is used in the model. Chile is the only country among all OECD countries with full technical efficiency throughout the years. The most efficient country is Poland. Poland has periodical full TE after 2003, except for in 2009. Turkey has a full efficiency score between the years of 2001-2003 and 2008-2009, while Mexico has a full efficiency score between 2000 and 2001 and in 2012. Greece, the economy of which has been experiencing a huge crisis lately, had full efficiency in 2012. However, Denmark, Iceland, and particularly Switzerland have the lowest performances over the years. A negative growth occurred in all countries, apart from Poland, at least once (especially in 2009) within 13 years. When we examine the relationship between growth and efficiency, the annual mean growth of Switzerland, which has the lowest efficiency, is 1.84 percent while Denmark's is 0.8 percent and Iceland's is 2.4 percent. Similarly, the annual growth rate of Chile, with the highest efficiency, is 4.46 percent, while that of Poland's is 3.83 percent and Turkey's rate is 4.44 percent. Upon examination of the samples, there exists a same directional tendency between growth and efficiency. The growth rate of a majority of the countries in 2009 is negative. However, the efficiency scores of those countries in 2009 are not the lowest. The efficiency score is below 50 percent in 2001 when the mean efficiency score is the lowest.

In Table 2, the consequences of the efficiency scores of the BCC model with variable return to scale (VRS) are generally determined to be greater than those of the CCR model. However, in this TE score, the most efficient years of efficient and inefficient countries do not overlap with the CCR model. Luxembourg, Chile, and Greece are fully efficient over 13 years while Korea, Switzerland, and Iceland are the least efficient countries. Poland, except for 2000 and 2001, and Israel, except for 2011 and 2012, are efficient during the study period. As a whole, standard deviation is highest in 2009 and the mean efficiency is lowest in 2012.

According to the table, standard deviation is highest in 2012 and mean efficiency is lowest in 2012. The results of the CCR model analysis indicate that the year 2012 has the second highest standard deviation. The efficiency levels vary between 0.4-0.55 in the CCR model analysis whereas the mean efficiency levels of the BCC analysis are higher at around 0.75-0.85.

In Figure $1, V R_{\text {mean }}$ and $C R_{\text {mean }}$ indicate the mean values of efficiency scores while $V R_{s d}$ and $C R_{s d}$ represent standard deviations according to the BCC and CCR models, respectively. The curve on the top of the figure indicates that the mean efficiency scores of the BCC model are higher than those of the CCR model and the mean efficiency has tendency to decrease $(<0.8)$ in 2012 . The $C R_{\text {mean }}$ curve is at its lowest level in $2001(<0.5)$ and continues to increase until 2011. On the contrary to the mean values, standard deviation in the BCC model is lower and the efficiency scores fluctuate less.

Figure 1. Mean Efficiency and DS Scores of the OECD Countries

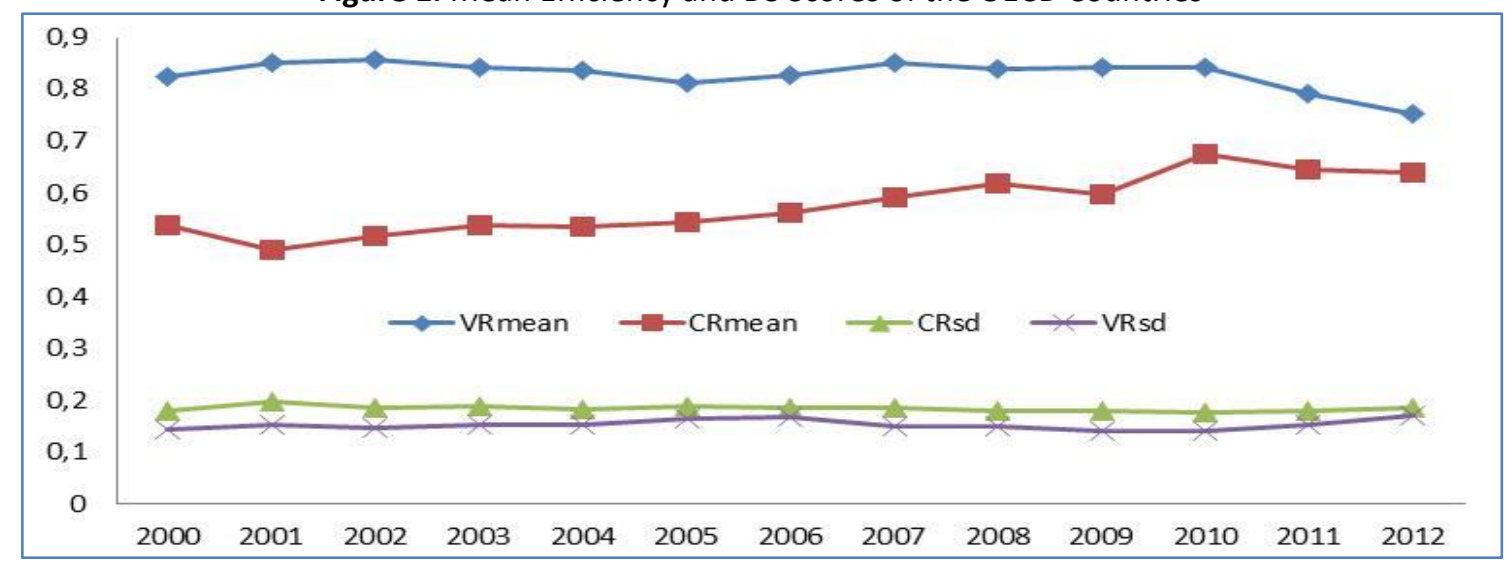




\subsection{Total factor productivity analysis with the Malmquist Index}

Scores of productivity and parameter anticipations of the countries are obtained individually with regards to TFP Analysis with output-oriented MI. Values for TFP Change (tfpch), Technical Change (techch), Efficiency Change (efch), Pure Efficiency Change (pech), and Scale Efficiency Change (sech) of the given countries are estimated in this analysis. The decomposition of MI for TFP is implemented as Ml= efch* techch $=$ pech $^{*}$ sech*techch. For instance, the MI value of Australia can be calculated as $\mathrm{Ml}_{\text {Australia }}=\mathrm{TFP}_{\text {Australia }}=0.984 * 0.991=0.991 * 0.993 * 0.990=0.975$.

Changes in efficiency values of each OECD country over 13 years are given in Table 3. TFP of OECD countries increased by 0.4 percent. Within the same period, the TFP values of 22 countries increased over the last year while those of 11 countries decreased. As seen in the table, such an increase results mainly from sech. Surprisingly, none of the countries' techch values exceeded one. In other words, TE values of those countries within the thirteen years are negative. The average loss in the TE is 1.1 percent. techch and pech values are below 1 whereas others are above 1 .

Table 3. Efficiency Changes of the OECD Countries

\begin{tabular}{|c|c|c|c|c|c|}
\hline Countries & efch & techch & pech & sech & tfpch \\
\hline Australia & 0.984 & 0.991 & 0.993 & 0.990 & 0.975 \\
\hline Austria & 1.018 & 0.992 & 0.996 & 1.022 & 1.011 \\
\hline Belgium & 1.010 & 0.992 & 0.996 & 1.014 & 1.002 \\
\hline Canada & 0.991 & 0.991 & 0.987 & 1.004 & 0.982 \\
\hline Czech Republic & 1.015 & 0.992 & 0.994 & 1.021 & 1.008 \\
\hline Denmark & 1.012 & 0.992 & 0.994 & 1.019 & 1.005 \\
\hline Estonia & 0.989 & 0.988 & 0.985 & 1.004 & 0.977 \\
\hline Finland & 1.012 & 0.992 & 0.995 & 1.016 & 1.004 \\
\hline France & 1.008 & 0.992 & 0.990 & 1.018 & 1.001 \\
\hline Germany & 1.018 & 0.992 & 0.993 & 1.025 & 1.010 \\
\hline Hungary & 1.007 & 0.989 & 0.988 & 1.019 & 0.996 \\
\hline Ireland & 1.063 & 0.982 & 1.014 & 1.048 & 1.044 \\
\hline Italy & 1.023 & 0.986 & 0.995 & 1.028 & 1.008 \\
\hline Luxembourg & 1 & 0.989 & 1 & 1 & 0.989 \\
\hline Netherlands & 1.023 & 0.992 & 0.995 & 1.028 & 1.016 \\
\hline New Zealand & 1.003 & 0.985 & 0.986 & 1.018 & 0.988 \\
\hline Norway & 0.993 & 0.976 & 0.999 & 0.994 & 0.969 \\
\hline Poland & 1.017 & 0.986 & 1.007 & 1.009 & 1.003 \\
\hline Portugal & 1.050 & 0.985 & 1.006 & 1.043 & 1.034 \\
\hline Slovak Republic & 1.024 & 0.988 & 1.001 & 1.023 & 1.011 \\
\hline Spain & 1.032 & 0.980 & 1.005 & 1.027 & 1.011 \\
\hline Turkey & 0.999 & 0.985 & 0.999 & 1.001 & 0.984 \\
\hline United Kingdom & 1.022 & 0.992 & 0.994 & 1.027 & 1.014 \\
\hline United States & 1.021 & 0.992 & 1.006 & 1.015 & 1.014 \\
\hline Sweden & 1 & 0.992 & 0.992 & 1.008 & 0.993 \\
\hline Switzerland & 1.013 & 0.992 & 1.002 & 1.012 & 1.006 \\
\hline Japan & 1.027 & 0.992 & 1.001 & 1.026 & 1.020 \\
\hline Mexico & 1 & 0.984 & 1 & 1 & 0.984 \\
\hline Korea & 1.020 & 0.992 & 0.999 & 1.021 & 1.013 \\
\hline Chile & 1 & 0.985 & 1 & 1 & 0.985 \\
\hline Slovenia & 1.015 & 0.992 & 0.991 & 1.025 & 1.007 \\
\hline Israel & 1.008 & 0.992 & 0.991 & 1.017 & 1 \\
\hline Iceland & 1.057 & 0.992 & 1.020 & 1.036 & 1.048 \\
\hline Greece & 1.046 & 0.983 & 1 & 1.046 & 1.028 \\
\hline Mean & 1.015 & 0.989 & 0.992 & 1.023 & 1.004 \\
\hline
\end{tabular}


Investigating the productivity increase in the Eurozone from a different point of view, Sondermann (2014) emphasizes that productivity results from regulations in the service sector (regulatory burden), R\&D investments, and the employment of highly-trained personnel. TFP increase around 0.4 percent in OECD countries might result from these factors. Australia is the only country whose scale efficiency is below one. In addition, all the efficiency values of Australia are below one. In the study carried out by Färe et al. (2006), Sweden and Denmark moved from well above average in 1965 to below average by 1998. Ireland showed the most dramatic productivity improvements in the sample.

In Krüger's (2003) study, which included OECD countries as well, the universal effect of productivity deceleration is indicated by the comparison of the sub-periods 1960-1973 and 1973-1990. With regards to TFP after 1973, not only TFP but also labor productivity measures decline in the majority of country groups, apart from in Asia. In particular, the fact that the deceleration affects the technological progress ratios indicates that all parts of the frontier function at least stagnate after 1973. When it comes to the positive side, there exists remarkable efficiency development keeping up in all country groups following 1973; however, getting behind movements was extensive before. The low level increase, which is not even one percent, in the TFP in the OECD countries following 2000 coincides with the abovementioned study's findings.

Table 4 represents the annual efficiency changes of the relevant countries. From this dynamic analysis, it is seen that $t f p c h$ is above one for five years but below one for seven years. In other words, TFP decreased for seven years within the 13 year-period in comparison to the reference year. TFP increased by 10.8 percent in the period of 2008/2009. In fact, the technical change value for the same period reached the highest value of all with an increase of 14 percent. We can conclude that the rise of TFP results from Technical Change. When Technical Change is considered to be positive for only three years, it is found that the period of 2008/2009 navigates in remarkably high levels.

In the Table, sech navigates above one for eight years. It can be understood that the most efficient of efficiency changes is sech. Furthermore, when the mean value is observed, it presents the highest growth of an average increase of 2.3 percent. In a study supporting the increase in TFP, Danquah et al. (2014) listed the variables increasing TFP for the OECD countries. According to this study, investment price, consumption share, trade openness, and the labor force are robustly correlated to TFP growth.

Table 4. Changes in Efficiency Scores

\begin{tabular}{cccccc}
\hline \multicolumn{1}{r}{ Years } & efch & techch & pech & sech & tfpch \\
\hline $2000 / 2001$ & 0.900 & 1.120 & 1.033 & 0.872 & 1.008 \\
$2001 / 2002$ & 1.063 & 0.958 & 1.005 & 1.057 & 1.018 \\
$2002 / 2003$ & 1.048 & 0.946 & 0.992 & 1.056 & 0.992 \\
$2003 / 2004$ & 0.994 & 0.991 & 0.999 & 0.995 & 0.985 \\
$2004 / 2005$ & 1.011 & 0.962 & 0.983 & 1.029 & 0.973 \\
$2005 / 2006$ & 1.031 & 0.945 & 1.006 & 1.025 & 0.975 \\
$2006 / 2007$ & 1.067 & 0.918 & 1.017 & 1.049 & 0.979 \\
$2007 / 2008$ & 1.046 & 0.970 & 0.995 & 1.051 & 1.014 \\
$2008 / 2009$ & 0.968 & 1.145 & 1 & 0.968 & 1.108 \\
$2009 / 2010$ & 1.136 & 0.903 & 0.996 & 1.141 & 1.025 \\
$2010 / 2011$ & 0.955 & 1.028 & 0.968 & 0.987 & 0.981 \\
$2011 / 2012$ & 0.985 & 1.012 & 0.979 & 1.005 & 0.996 \\
\hline mean & $\mathbf{1 . 0 1 5}$ & $\mathbf{0 . 9 8 9}$ & $\mathbf{0 . 9 9 2}$ & $\mathbf{1 . 0 2 3}$ & $\mathbf{1 . 0 0 4}$ \\
\hline
\end{tabular}

Figure 2 provides changes in TFP variables and it is observed that a fluctuation exist especially between 2008 and 2011. In the study by Färe et al. (2006), labor and multi-factor productivity improved for most of the countries in their sample. 
Figure 1. Trends of Changes in Efficiencies over Time

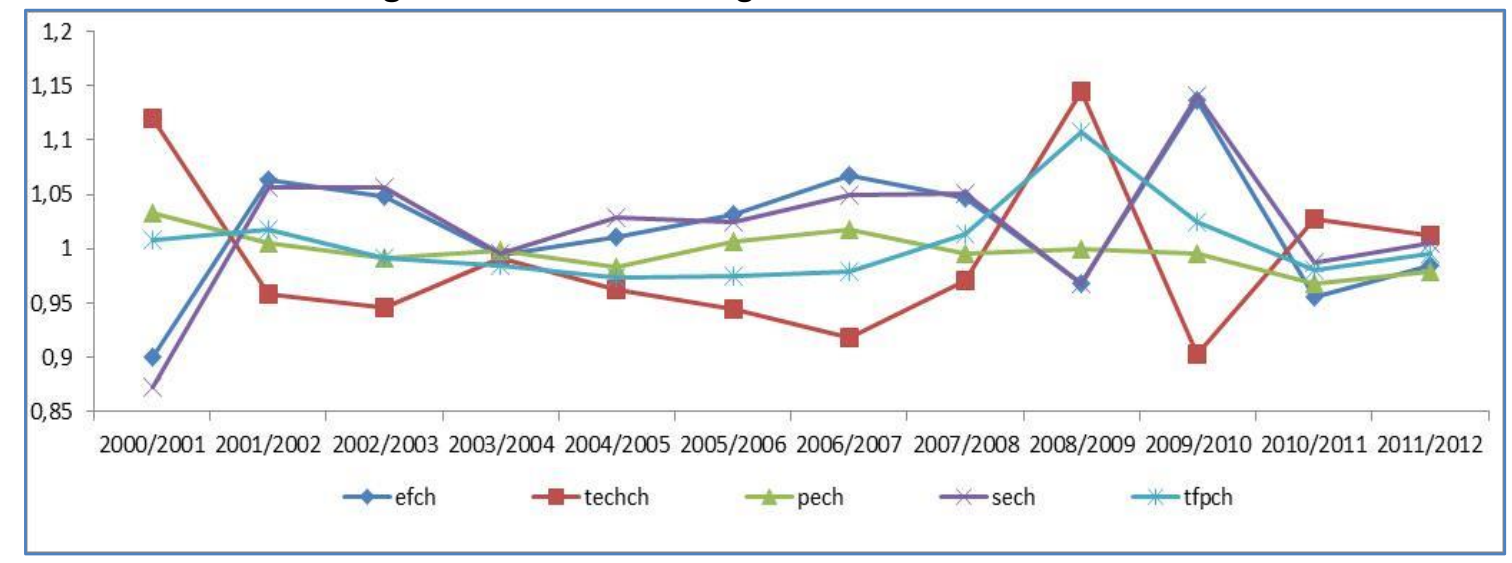

Table 5. Changes in Variables over the Investigated Period

\begin{tabular}{|c|c|c|c|c|c|c|}
\hline Countries & grpc & grpk & ggdp & $\operatorname{grpc}_{13}$ & grpk $_{13}$ & $\operatorname{ggdp}_{13}$ \\
\hline Australia & 54.61 & 73.03 & 12.90 & 4.20 & 5.62 & 0.99 \\
\hline Austria & -4.35 & 59.54 & 8.69 & -0.33 & 4.58 & 0.67 \\
\hline Belgium & 4.72 & 22.27 & 7.46 & 0.36 & 1.71 & 0.57 \\
\hline Canada & 32.73 & -4.23 & 6.18 & 2.52 & -0.33 & 0.48 \\
\hline Czech Republic & 23.81 & 119.30 & 36.02 & 1.83 & 9.18 & 2.77 \\
\hline Denmark & -0.59 & 27.50 & 4.97 & -0.05 & 2.12 & 0.38 \\
\hline Estonia & 84.47 & 435.35 & 47.22 & 6.50 & 33.49 & 3.63 \\
\hline Finland & 8.19 & 20.77 & 13.76 & 0.63 & 1.60 & 1.06 \\
\hline France & 6.43 & 14.43 & 7.42 & 0.49 & 1.11 & 0.57 \\
\hline Germany & -7.91 & 25.48 & 4.20 & -0.61 & 1.96 & 0.32 \\
\hline Hungary & 20.99 & 93.90 & 20.40 & 1.61 & 7.22 & 1.57 \\
\hline Ireland & -37.36 & 78.47 & 19.58 & -2.87 & 6.04 & 1.51 \\
\hline Italy & -18.65 & 14.75 & -5.74 & -1.43 & 1.13 & -0.44 \\
\hline Luxembourg & 8.05 & -19.68 & -8.80 & 0.62 & -1.51 & -0.68 \\
\hline Netherlands & -11.60 & 18.84 & 6.65 & -0.89 & 1.45 & 0.51 \\
\hline New Zealand & 23.08 & 53.88 & 9.27 & 1.78 & 4.14 & 0.71 \\
\hline Norway & 32.17 & 145.05 & 5.74 & 2.47 & 11.16 & 0.44 \\
\hline Poland & 31.06 & 103.88 & 46.00 & 2.39 & 7.99 & 3.54 \\
\hline Portugal & -33.18 & 127.79 & 10.87 & -2.55 & 9.83 & 0.84 \\
\hline Slovak Republic & 42.32 & 100.39 & 57.75 & 3.26 & 7.72 & 4.44 \\
\hline Spain & -15.30 & 55.74 & 8.68 & -1.18 & 4.29 & 0.67 \\
\hline Turkey & 83.39 & 211.88 & 62.07 & 6.41 & 16.3 & 4.77 \\
\hline United Kingdom & -6.69 & 6.25 & 10.19 & -0.51 & 0.48 & 0.78 \\
\hline United States & 0.35 & 26.00 & 18.2 & 0.03 & 2.00 & 1.40 \\
\hline Sweden & 25.49 & -1.48 & 14.82 & 1.96 & -0.11 & 1.14 \\
\hline Switzerland & -1.73 & 20.96 & 5.12 & -0.13 & 1.61 & 0.39 \\
\hline Japan & -11.38 & 25.12 & 12.03 & -0.88 & 1.93 & 0.93 \\
\hline Mexico & 9.61 & 25.46 & -0.01 & 0.74 & 1.96 & 0.00 \\
\hline Korea & 17.12 & 158.65 & 36.26 & 1.32 & 12.20 & 2.79 \\
\hline Chile & 88.28 & 24.26 & 21.00 & 6.79 & 1.87 & 1.62 \\
\hline Slovenia & 12.76 & 135.52 & 23.74 & 0.98 & 10.42 & 1.83 \\
\hline Israel & 0.86 & -1.66 & 0.96 & 0.07 & -0.13 & 0.07 \\
\hline Iceland & -32.65 & 17.99 & 19.34 & -2.51 & 1.38 & 1.49 \\
\hline Greece & -24.97 & 35.41 & 14.21 & -1.92 & 2.72 & 1.09 \\
\hline
\end{tabular}

Table 5 presents certain different results regarding the OECD countries. The percent change in real physical capital per worker (grpc) and mean percentage of change for thirteen years are given in the table $\left(\mathrm{grpc}_{13}\right)$. Similarly, grpk indicates the percentage of change in real human capital per worker, and ggdp indicates the mean percentage of change of real GDP per worker. The digit 13, added to the values, indicates 
mean percentages of change over thirteen years. The findings of the table indicate that 12 countries incurred losses of physical capital per worker and the others increased this ratio within thirteen years. Spain, Portugal, and Greece, the latter of which has shown signs of serious economic constriction in recent years, incurred losses of physical capital. However, according to the table, some countries such as Iceland, Japan, and even Germany, England, and the Netherlands suffer from the same situation. At the same time, the increases of physical capital per worker are the highest in the countries like Poland, Hungary, the Czech and Slovak Republics, and Estonia among former Soviet Union countries. The increase in Estonia is particularly high. We can conclude that Scandinavian countries and Turkey are among the countries that increased their physical capital significantly. Estonia, Chile, and Turkey are the top three countries to have increased their physical capital per worker within the given period. If we remember the table of TE scores, we can see that Chile has had the highest efficiency during the whole period; Turkey and Poland are also among the countries with highest efficiency. Iceland is, according to the same data, among countries with the lowest performances. We can conclude that physical capital increase is reflected in efficiency.

In the same table, different results are seen upon the examination of human capital. According to the data, it is understood that only four countries (Luxembourg, Canada, Israel, and Sweden) incurred losses of human capital per worker during the time period. Although this is a low ratio, it is noteworthy. The digit is negative only for Italy and Luxembourg when we examine $g g d p$ among countries. The relevant data for Israel is below one $(<1)$. A decrease exists in both grpk and ggdp for Luxemburg; it is a low level, however. As seen in Table 3, while mean TFP values of Luxembourg and Canada are below one, it does not show any changes in Israel.

Figure 3 indicates the growth $(y)$ of three countries that increased their physical capital the most and those that lost their human capital. Growth rates of five countries in 2009, except for Israel, are negative as a common feature. However, the growth in 2001 is negative only for Israel and Turkey. In general, growth trends of the three countries incurring losses of human capital navigate below those of the other three countries. Low growth rates might have decreased the attraction to these countries.

Figure 3. Growth Trends of the 3 Best and 3 Worst OECD Countries

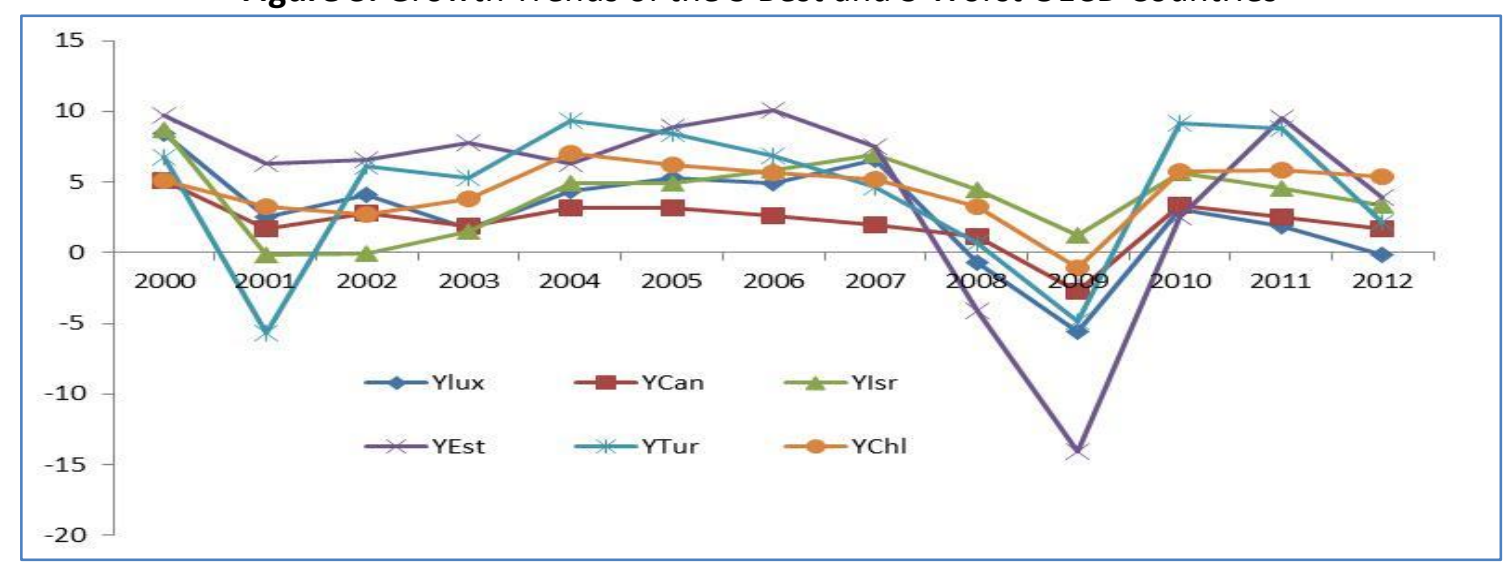

\subsection{Convergence}

Convergence is the approximation of two economies in terms of growth. According to technological innovation theory, diffusion is one of the ways that innovation is transformative. Innovation in a developed nation can spread to developing nations. Thus, developing countries stimulates economic growth, which enables them to converge with developed economies (Abramovitz 1986).

Changes in the logarithm of real GDP per worker (dlgdp), TFP (tfpch), and efficiency (efch) variables are used in $\beta$-convergence tests. The values in the first row of Table 6 indicate that the $F$ statistic is significant according to $d l g d p$ estimation and the model is significant. On the other hand, the Durbin-Watson value, which represents autocorrelation, is acceptable. The $\beta$-convergence value for $d l g d p$ is significant with a significance level of 1 percent, which indicates convergence. 
Nevertheless it is not possible to arrive at a similar conclusion for the dependent variables tfpch (in the second row) and efch (in the last row). $\beta$-convergence values in both estimations are not statistically insignificant and it is hard to say whether these variables cause convergence or divergence.

Table 6. Regressions for $\beta$-convergence

\begin{tabular}{|c|c|c|c|c|}
\hline \multicolumn{5}{|c|}{ Dependent Variable*: dlgdp } \\
\hline Variables & Coefficient & Std. Error & t-Statistic & Prob. \\
\hline LGDP & -0.284258 & 0.044992 & -6.318024 & 0.0000 \\
\hline $\mathrm{C}$ & 3.240360 & 0.490573 & 6.605261 & 0.0000 \\
\hline R-squared & 0.555045 & \multirow{3}{*}{\multicolumn{2}{|c|}{ Durbin-Watson stat }} & \\
\hline F-statistic & 39.91743 & & & 2.592135 \\
\hline Prob (F-statistic) & 0.000000 & & & \\
\hline \multicolumn{5}{|c|}{ Dependent Variable: tfpch } \\
\hline LGDP & 0.007195 & 0.009040 & 0.795879 & 0.4320 \\
\hline $\mathrm{C}$ & 0.925708 & 0.098570 & 9.391407 & 0.0000 \\
\hline R-squared & 0.019410 & \multirow{3}{*}{\multicolumn{2}{|c|}{ Durbin-Watson stat }} & \\
\hline F-statistic & 0.633424 & & & 1.850105 \\
\hline Prob (F-statistic) & 0.431967 & & & \\
\hline \multicolumn{5}{|c|}{ Dependent Variable: efch } \\
\hline LGDP & 0.005306 & 0.009153 & 0.579705 & 0.5662 \\
\hline C & 0.957472 & 0.099796 & 9.594301 & 0.0000 \\
\hline R-squared & 0.010393 & \multirow{3}{*}{\multicolumn{2}{|c|}{ Durbin-Watson stat }} & \\
\hline F-statistic & 0.336058 & & & 1.605166 \\
\hline Prob (F-statistic) & 0.566173 & & & \\
\hline
\end{tabular}

${ }^{*}$ \# of observations is 34 .

The following Figure 4 provides enough information on $\sigma$-convergence. As stated before $\sigma$ convergence indicates income dispersion. However, $\beta$-convergence is a must for the relevant dispersion. Thus it is stated that the cross-section regression analysis above has $\beta$-convergence, yet the same result could not be achieved for tfpch and efch variables. The figure indicates that standard deviation of log GDP per worker (SDgdp) follows a negative pattern. The same dispersion can be seen in the regression equation and the inclination of the graphic. On the other hand, standard deviation of log TFP (SDtfp) value does not show similar tendencies. Even though it is not readily apparent, the curve deviates dramatically in 2009 and tends to decline following this period. Linear regression values present slightly positive parameter values.

Figure 4. Standard Deviations of the GDP and TFP

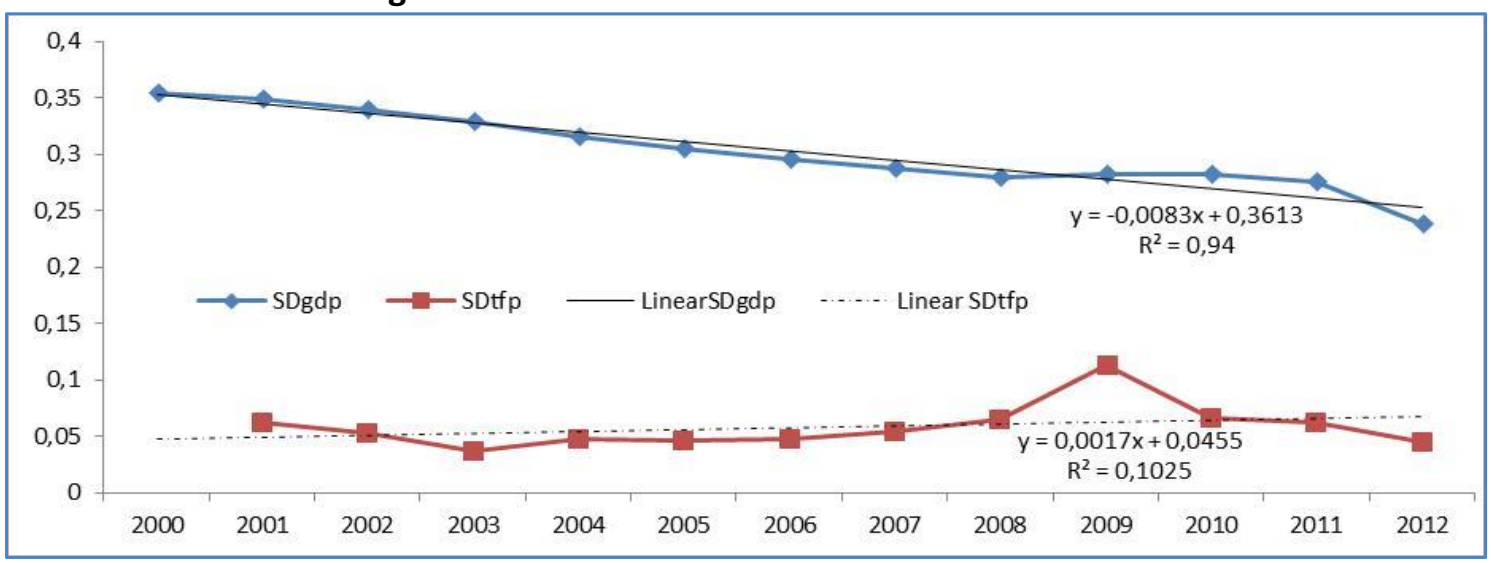

It is useful to remember Kumar and Russell (2002), who suggest a different thesis regarding convergence. The authors criticized the empirical studies of convergence by stating that the technological progress was not unbiased in their study, and they emphasized that convergence was only found among developed countries in the production frontier on the world scale by using intensive capital-including technologies. That is out of the question for countries with lower incomes. Only developed nations benefit from technological innovations. The study analyzed 57 countries. As all the OECD countries do not benefit 
from the same technological innovations and they do not have similar income levels, we should not expect to find convergence in our study.

Sondermann (2014) obtained some results by using a time series in convergence analysis of Eurozone countries. In his study, he investigated the agriculture, service, and manufacturing sectors and their sub divisions and tested convergences in the relevant sectors. According to his results, convergence is observed in few sectors and no average convergence is observed. For example, while convergence is observed in agriculture, transportation, and nonmarket services between 1970 and 1998, no convergence is observed for total economies.

The findings of Färe et al. (2006) on convergence in OECD countries is that cross-section results support convergence in principle, although when they take advantage of the decomposition of productivity into technical change, capital deepening and catch-up, they find that technical change (especially input biased technical change) is a source of divergence.

\section{Conclusion}

In our study TE scores, productivity, and convergence of the OECD countries between 2000 and 2012 are examined in 34 countries. In determining the efficiency scores of DEA, an output oriented CCR model is applied. Chile is found to be the only country with full efficiency throughout the period followed by Poland, Turkey, and Mexico. Denmark, Iceland, and particularly Switzerland have had the lowest performance over the 13 years. The efficiency score is the lowest in 2001.

The GDP of Chile increased 4.5 percent over thirteen years, ranking second among member countries. After ranking first among the member countries, Estonia experienced severe economic shrinkage in 2008 and 2009. Four countries with the lowest performance experienced fluctuations over thirteen years and tended to exhibit stagnation towards the end of the study period. The average growth rate of OECD countries over thirteen years is 1.87 percent, whereas the average growth rate of Denmark is below one. Switzerland is a striking example because the growth rate of the country is around 4 percent in the beginning of the study period but drops to 1.1 percent in the end.

TFP, which is calculated in geometric means, showed an increase of 4 percent. While TFP values of 22 countries increased in comparison to reference year, those of 12 countries decreased within the given period.

A substantial part of the increase results from scale efficiency Scale Change (sech). Furthermore, it is observed that TFP is above one for five years, but below one for seven years. In other words, TFP decreased for seven years in comparison to the reference year over 13 years. In the period of 2008/2009, TFP increased by 10.8 percent. The technical change value for the same period reached the highest value of all with an increase of 14 percent. We can conclude that the high level of TFP results from Technical Change. In order to investigate the presence of convergence among the OECD countries, it is determined that standard deviations of TFP logarithmic values do not indicate regular decline. In addition, conditional $\beta$ value is found to be above zero and significant in the panel regression analyses carried out using both TFP values and logarithmic values of GDP per worker. According to these results, no convergence occurs in the OECD countries in the model where capital per worker and human capital per worker are used as inputs.

Changes in logarithm of GDP per worker, TFP, and efficiency variables are used to test the $\beta$ convergence and $\sigma$-convergence in OECD countries. A cross-sectional regression analysis of $d$ lgdp indicates that the $\beta$ value is negative and significant. However, we could not arrive at a similar conclusion for tfpch and efch variables, the $\beta$ values of which were not significant. We can conclude that these variables show divergence rather than convergence. The graphic illustration of $\sigma$-convergence shows that the standard deviation of the $d l g d p$ variable tends to be downwards and negative in the study period.

At the same time, the graphic illustration of $\sigma$-convergence indicates that the standard deviations of dlgdp (SDgdp) variable in the study period tend to be downwards and negative. However, we cannot make 
similar observations for the standard deviations of logTFP (SDtfp). Total Factor Productivity does not seem to have any impact on $\sigma$-convergence or $\beta$-convergence.

The average annual growth rate of some OECD countries is around 4.5 percent while the relevant figure is reported to be 0.5 percent for Portugal and Greece. Such a difference is expected to have a negative impact on convergence. Likewise, the difference between top 10 percent and bottom 10 percent is 7 percent in 1980s, while the figure is almost 10 percent in 2012 (http://oe.cd/idd) which indicates an unequal distribution of income.

In general, Latin America and Eastern European countries, (including Turkey), which participated in OECD community later, have more efficient indications in comparison to other countries. A noteworthy detail is that human capital per worker loss occurs in countries such as Canada, Luxembourg, and Sweden, which have considerably highly-qualified labor and high incomes, and in Israel, where political unrest and fear of war is always on the agenda.

In this static comparative analysis regarding convergence in the OECD countries, some complementary results have been found. However; it may be argued that when dynamic processes or DEAWindow analysis are utilized to investigate the convergence, the same results may not be reached. We feel confident to leave that option to another study investigating the convergence phenomenon.

\section{End Notes}

1. The value of 8 coefficient is calculated using Barro and Sala-i-Martin's $(1991,1992)$ approach. $\frac{1}{T} \log \left(y_{i} / y_{i, t-T}\right)=x^{*}+\log \left(\hat{y}_{i}^{*} / \hat{y}_{i, t-T}\right)\left(1-e^{-\beta T}\right) / T+u_{i t}$

In this equation, i represents economy, $t$ represents time, $y_{i t}$ represents output per capita, $x^{*}$ represents the steady state grow rate per capita, $\hat{y}_{i t}$ is output per active labour, $\hat{y}_{i t}^{*}$ is steady-state output level per active labour, and $T$ is the observation interval. Inspired by this equation, we have achieved some results by adding other variables to the panel regression.

\section{References}

Abramovitz, M. (1986). Catching up, forging ahead, and falling behind. Journal of Economic History, 46(2), 385-406.

Banker, R.D., Charnes, A., \& Cooper, W.W. (1984). Some models for estimating technical and scale inefficiencies in data envelopment analysis. Management Science, 30(9), 1078-1092.

Barro, R.J., \& Sala-i-Martin, X. (1992). Convergence. Journal of Political Economy, 100(2), 223-251.

Barro, R.J., Sala-i-Martin, X., Blanchard, O.J., \& Hall, R.E., (1991). Convergence across states and regions. Brookings Papers on Economic Activity, 1991(1), 107-182.

Barro, R.J., \& Sala-i-Martin, X. (1995). Economic growth. Cambridge, MA: MIT Press.

Cass, D. 1965. Optimum growth in an aggregative model of capital accumulation. Review of Economic Studies, 32(91), 233-240.

Caves, D.W., Christensen, L.R., \& Diewert, W.E. (1982). The economic theory of index numbers and the measurement of input, output, and productivity. Econometrica, 50(6), 1393-1414.

Charnes, A., Cooper, W.W., \& Rhodes, E. (1978). Measuring the efficiency of decision making units. European Journal of Operational Research, 2, 429-444.

Charnes, A., Cooper, W.W., \& Rhodes, E. (1979). Short communication: Measuring the efficiency of decision making units. European Journal of Operational Research, 3, 339.

Chen, P.C. \& Yu, M.M. (2014). Total factor productivity growth and directions of technical change bias: Evidence from 99 OECD and non-OECD countries. Annals of Operations Research, 214(1) $)$ 143-165.

Coelli, T.J., Rao, D.S.P., O'Donell, C.J., \& Battese, G.E. (2005). An introduction to efficiency and productivity analysis. $2^{\text {nd }}$ ed. New York: Springer. 
Cooper, W.W., Seiford, L.M., \& Zhu, J. (2011). Handbook on data envelopment analysis. $2^{\text {nd }}$ ed. New York: Springer.

Danquah, M., Enrique, M.B., \& Bazoumana, O. (2014). TFP growth and its determinants: A model averaging approach. Empirical Economics, 47(1), 227-251.

Debreu, G. (1951). The coefficient of resource utilization. Econometrica, 19(3), 273-292.

Dowrick, S., \& Nguyen, D.T. (1989). OECD Comparative economic growth 1950-85: catch-up and convergence. The American Economic Review, 79(5), 1010-1030.

Färe, R. (1988). Fundamentals of production theory. Heidelberg: Springer-Verlag.

Färe, R., Grosskopf, S., \& Dimitri, M. (2006). Productivity growth and convergence in the European Union. Journal of Productivity Analysis, 25(1-2), 111-141.

Färe, R., Grosskopf, S., \& Margaritis, D. (2011). Malmquist productivity indexes and DEA. In Handbook on Data Envelopment Analysis edited by W.W. Cooper et al., 127-149. Norwell: Springer.

Färe, R., Grosskopf, S., Lindgren, B., \& Roos, P. (1992). Productivity changes in Swedish pharmacies 1980-1989: A nonparametric Malmquist Approach. Journal of Productivity Analysis, 3(1-2), 85-101.

Färe, R., Grosskopf, S., Lindgren, B., \& Roos, P. (1994a). Productivity developments in Swedish hospitals: A Malmquist output index approach. In Data Envelopment Analysis: Theory, methodology and applications, edited by $A$. Charnes et al., 253-272. Norwell: Springer.

Färe, R., Grosskopf, S., Norris, M., \& Zhang, Z. (1994b). Productivity growth, technical progress, and efficiency change in industrialized countries. The American Economic Review, 84(1), 66-83.

Farrell, M.J. (1957). The Measurement of productive efficiency. Journal of the Royal Statistical Society, 120(3), 253-281.

Hseu, J.S., \& Shang, J. K. (2005). Productivity changes of pulp and paper industry in OECD countries, 1991-2000: A nonparametric Malmquist Approach. Forest Policy and Economics, 7(3), 411-422.

Koopmans, T.C. (1965). On the concept of optimal economic growth. in The Econometric Approach to Development Planning, Amsterdam: North Holland.

Koopmans, T.C. (1951). An analysis of production as an efficient combination of activities. In Activity Analysis of Production and Allocation, edited by T. C. Koopmans. New Jersey: John Wiley \& Sons.

Krüger, J.J. (2003). The global trends of total factor productivity: Evidence from the non-parametric Malmquist index approach. Oxford Economic Papers, 55(2), 265-286.

Kumar, S., \& Managi, S. (2012). Productivity and convergence in India: A State-level analysis. Journal of Asian Economics, 23(5), 548-559.

Kumar, S., \& Russell, R.R. (2002). Technological change, technological catch-up, and capital deepening: Relative contributions to growth and convergence. The American Economic Review, 92(3), 527-248.

Kumbhakar, S.C., \& Lovell, C.A.K. (2000). Stochastic frontier analysis. U.K.: Cambridge University Pres.

Lábaj, M., Luptáčik, M., \& Nežinský, E. (2014). Data envelopment analysis for measuring economic growth in terms of welfare beyond GDP. Empirica, 41(3) , 407-424.

Lee, J. (2009). Trade, FDI, and Productivity convergence: A dynamic panel data approach in 25 countries. Japan and the World Economy, 21(3), 226-238.

Madsen, J.B. (2007). Technology spillover through trade and TFP convergence: 135 years of evidence for the OECD countries. Journal of International Economics, 72(2), 464-480.

Malmquist S. (1953). Index number and indifferences surfaces. Trabajos de Estatistica, 4, 209-242.

Mankiw, N.G., Romer, D., \& Weil, D.N. (1992). A Contribution to the empirics of economic growth. Quarterly Journal of Economics, 107(2), 407-437.

Margaritis, D., Färe, R., \& Grosskopf, S. (2007). Productivity, convergence and policy: A study of OECD countries and industries. Journal of Productivity Analysis, 28(1-2), 87-105.

Maudos, J., Pastor, J.M., \& Serrano, L. (2000). Convergence in OECD Countries: Technical change, efficiency and productivity. Applied Economics, 32(6), 757-765.

Raab, R.L., \& Feroz, E.H. (2007). A Productivity growth accounting approach to the ranking of developing and developed nations. The International Journal of Accounting, 42(4), 396-415.

Rivera-Batiz, L.A., \& Romer, P.M. (1991). International trade with endogenous technological change. European Economic Review, 35(4), 971-1001.

Romer, P. (1986). Increasing returns and long run growth. Journal of Political Economy, 99, 500-521. 
Shestalova, V. (2003). Sequential Malmquist indices of productivity growth: An application to OECD industrial activities. Journal of Productivity Analysis, 19, 211-226.

Solow, R.M. (1956). A Contribution to the theory of economic growth. Journal of Economics, 70, 65-94.

Solow, R.M. (1957). Technical change and the aggregate production function. Review of Economics and Statistics, 39(3), 312-320.

Sondermann, D. (2014). Productivity in the Euro area: Any evidence of convergence?. Empirical Economics, 47(3), 9991027.

Swan, T.W. (1956). Economic growth and capital accumulation. Economic Record, 32(63), 334-361.

Yörük, B.K., \& Zaim, O. (2005). Productivity growth in OECD countries: A comparison with Malmquist indices. Journal of Comparative Economics, 33(2), 401-420.

Sala-i-Martin, X. (1996a). Regional cohesion: Evidence and Theories of regional growth and convergence. European Economic Review, 40, 1324-1352.

Sala-i-Martin, X. (1996b). The classical approach to convergence analysis. The Economic Journal, 106(437), 1019-1036. 